\title{
Why Did the Large Blue Become Extinct in Britain?
}

Jeremy Thomas

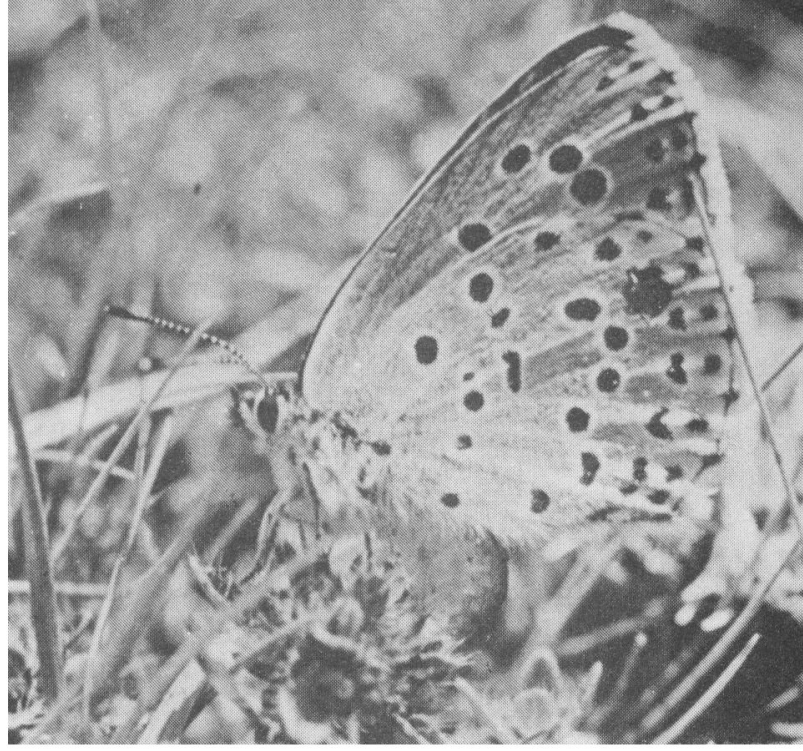

In 1979 the Nature Conservancy Council revealed that the large blue butterfly Maculinea arion was probably extinct in Britain, despite much research and valiant efforts to save it. The author, a member of the Institute of Terrestrial Ecology, who since 1972 has been engaged full time on the research and conservation work for the butterfly, tells the story as it is now known.

It is believed that the large blue butterfly became extinct in Britain in 1979 . It is over 50 years since any British butterfly was lost, but the demise of the large blue is particularly sad because it was one of our most attractive species and because it has a particularly interesting life cycle. Eggs are laid on thyme Thymus praecox, on which the young larvae feed, but older larvae are carried by red (Myrmica spp.) ants to their underground nests, where they live for nine months, feeding on ant grubs.

The large blue has always been a local species in Britain, having been recorded from only about 90 sites in the past 150 years. These colonies declined over much of that period, but the butterfly still occurred on at least 30 sites in the early 1950s in the Cotswolds, Somerset, Devon and Cornwall. Some of these held large populations. Unfortunately, a severe decline occurred in the next ten years, and by the mid 1960s only four colonies were known. These became extinct in 1967, 1971, 1973 and 1979.

About half of Britain's large blue colonies were destroyed by fundamental changes to their sites, such as by ploughing, afforestation, urbanisation, and quarrying. More would have been destroyed but for the action of conservationists, whose exertions to save the large blue have been great, extending over 40 years and culminating, in 1962 , in the formation of a Joint Committee for the Conservation of the large blue butterfly to coordinate projects. Unfortunately, despite the many measures that were taken, the large blue continued to decline as rapidly on nature reserves as on other sites because, as is now apparent, the precise environmental conditions needed for a viable colony were not understood, and subtle adverse changes were occurring on sites, unrecognised and unchecked. 


\section{The Research}

By 1972 it was clear that a greater understanding of the ecology of the large blue was needed if there was to be any hope of saving it. Full time research was started by the Nature Conservancy, and continued with the foundation of the Institute of Terrestrial Ecology. This revealed some of its requirements and showed grave and increasing deficiencies in the habitat of remaining and former sites. In particular, it was found that only one species of ant, Myrmica sabuleti, was a suitable host for a colony, and that survival was so poor in nests of the other common grassland Myrmica, M.scabrinodis, that a colony was unlikely to survive if that ant predominated. It was also found that the status of these ants was mainly determined by the intensity of grazing. M.sabuleti is confined to a very close-cropped sward on large blue sites, and is rapidly replaced by the unsuitable $M$.scabrinodis if grazing is only slightly relaxed. If grazing is abandoned, almost all Myrmica nests disappear rapidly, especially on acid soils if scrub invasion is also unchecked. In contrast, thyme persists in a wide range of sward heights, and flourishes under grazing regimes that support either M.sabuleti or M.scabrinodis. After many years it, too, declines on ungrazed sites.

An analysis of the habitat of all former and existing large blue sites in Britain showed that, with the exception of the last site, none was being grazed intensively enough to support the high densities of M.sabuleti that are needed, although several were being lightly grazed and had an abundance of thyme and M.scabrinodis. Most had been entirely abandoned and had lost the majority of their ants. This relaxation in grazing occurred on most sites after the mid 1950 s, when myxomatosis reduced rabbit populations and when the changing economics of agriculture gave a poor return from grazing 'unimproved' sites to the required intensity. Thus, because of changing land management, the specialised conditions needed by the large blue were unlikely to be produced as a by-product of agriculture after the mid 1950s, and its survival as a British species was only likely to continue on nature reserves. Unfortunately, these were acquired rather late to save this insect, and there was a further delay in obtaining the knowledge of how best to manage them.

The last British colony became extinct for other reasons than habitat destruction or undergrazing. This site was maintained in a suitable condition (through giving generous terms to the tenant farmer) such that a population of the large blue would be expected to increase in most years, as indeed occurred continuously from 1964 to 1973 . Unfortunately, the breeding area was so small that it could not support a population large enough to withstand an occasional sequence of adverse events. Such a sequence occurred in the mid 1970s. By 1973, the population had increased so much that the low capacity of the site was exceeded and severe overcrowding occurred, causing heavy extra mortalities and reducing the population from about 300 to 100 adults in 1974 . (These mortalities mainly occurred in ants nests, with up to 40 larvae entering a single nest. Most nests can support only one large blue, and in cases of overcrowding all the larvae died). In perhaps 14 out of 15 years, the population would increase after this under the then habitat conditions, but, unfortunately, before this could occur, severe droughts in 1975 and 1976 further reduced the colony, so that only about 16 adults emerged in 1977. Extreme summer drought can be very harmful to egg-laying and to the condition of ant nests, but has only occurred at a damaging intensity about once every 25 years 
Above Ant with a butterfly larva

in the present century up to 1975 .

By 1976, enough was known of the requirements of the large blue to see that its last site was probably too small to support a colony indefinitely. Plans were made to enlarge and improve the breeding areas so that they could eventually support 5000 adult large blues before overcrowding occurred. This worked well, and by 1978 the carrying capacity had already increased from about 300 to about 700 adults. Experiments showed that, if only this had been done before 1973, the population would have spread into these adjoining areas and would probably have increased in that year, instead of experiencing the most severe annual decline yet recorded.

Despite the improvement to the last site, no recovery of the large blue could be confidently predicted after 1977 , even given 'average' years, because adult numbers had fallen to so low a level that inverse density-dependent and chance factors could also be important. For example, by chance in 1977 probably only five (possibly six or seven) individuals of the estimated population of 16 adults were females, although there are usually almost equal numbers of the two sexes. This dearth of females was compounded by the fact that the last one (probably two) females to emerge failed to mate because all the earlieremerging and short-lived males had already died. Thus, probably only about 25 per cent of the 1977 population started the adult period as fertilised females, instead of the usual proportion of about 50 per cent of the population when numbers are higher.

For these reasons, few eggs were laid in 1977 and it was predicted that the emergence of large blues in 1978 would be even lower than in 1977 and even more liable to extinction through inverse density and chance effects. The Nature Conservancy Council and the Joint Committee therefore decided to rear the 1978 adults in semi-captivity, in an eleventh hour, 'one-off' attempt to increase numbers to a viable level. It was hoped to achieve this by prolonging the lives of males, thus increasing the chances of females being mated; by increasing the number of eggs laid per female by caging them over thyme; by rearing these eggs in captivity; and by reintroducing the young larvae to M.sabuleti nests on the site.

The fears that prompted this operation were realised in 1978 when only five adults (two females, three males) emerged over the long period of 31 days. The large blue has a short life expectancy in the wild, and the extended emergence meant that there was a less than 50 per cent chance that even one female would have paired in the wild through no male being alive at the critical times, and 
only a 7 per cent chance that both would have paired. Thus the colony would probably have become extinct in 1978 had no action been taken. Instead, all five adults were kept alive for much longer than their natural lifespans, but only one female paired. This was because no male was in peak condition when the other female was receptive. However, by the end of the season, 59 larvae had been introduced to $M$.sabuleti nests on the site, which is about five times the average number produced from one female in the wild. It was thought that these would still produce too few adults in 1979 for safety, although numbers would be considerably higher. It was decided, therefore, to repeat the operation in 1979 in a second attempt to increase numbers to a viable level.

In 1979, 22 adults emerged, representing an exceptionally high survival in ant nests and indicating that the site was still as good as it had ever been for this species. Unfortunately, these adults failed to pair and only a few sterile eggs were laid by virgin females. The reason for this failure is not understood, although it is not thought to be caused by inbreeding. A more likely explanation is that the pairing of captive butterflies, which is always difficult and unpredictable, sadly, was unsuccessful on this occasion. This possibility was recognised before the operation, but was considered to be a lesser danger than the near certainty of extinction if no action was taken.

Thus what is believed to be the last colony of the large blue in Great Britain became extinct in 1979. Since this news was released, there have been a large number of sightings reported from all parts of the British Isles, as have indeed been received every year. Unfortunately, none seems to be very likely and most can be immediately dismissed, mainly as misidentifications of the common blue Polyommatus icarus. There is still a faint hope that some colony exists, but this is unlikely in the light of the many surveys that have been made and the rarity of suitable habitat occurring, by chance, as a result of modern farming practices. However, another survey will be made of all possible sites in 1980 .

In the meantime, former sites will be maintained or improved to provide suitable habitat conditions. If no British colony is discovered in the next few years, an introduction using continental stock may be considered.

\section{The Lessons}

Much has been learnt from the history of the conservation of the large blue, despite its disappointing outcome. Its decline to possible extinction was recognised at least 100 years before the event, and active conservation started more than 40 years ago. Since then, many measures have been taken, of which only a few have been described in the literature. These involved a very large expenditure of enthusiasm, manpower, and money, yet the butterfly still became extinct. With hindsight, it is clear that the butterfly could almost certainly have been saved, if only the measures that were started in the mid 1970 s had been taken five or more years earlier. The reason why they were not is entirely due to the fact that the butterfly's ecological requirements were not understood until after they had been studied intensively; this did rot occur until the 1970s. The will and resource needed to save the large blue were certainly available in the $1960 \mathrm{~s}$, and probably earlier (when the required action would also have been much easier and cheaper). Instead, most of the measures that were taken at that time can now be shown to have been irrelevant or actually harmful to the butterfly's needs. Some measurements taken were, on the other hand, beneficial (e.g. discovering colonies, preventing ploughing of 
sites, deterring collectors) but these did not rectify the main adverse changes.

This account is not intended as a criticism of early conservation efforts. There were few precedents for conserving an insect when the first measures were taken, and most were pioneering and enlightened for their time. It was only after they had been tried, and were found wanting, that it became apparent that the specialised requirements of a rare insect were unlikely to be guessed from a mere knowledge of the life cycle, and were only likely to be revealed as a result of full-time research. Having learnt this lesson, it is hoped that more will be learnt about the requirements of other endangered species at an earlier stage in their decline, so that the resources now available can be used more constructively. This applies to both common and rare species, but is a more urgent problem for the latter. Experience from the large blue suggests that the sooner this is done, the easier and quicker will be the research and the measures needed, and success will be more probable, and more cheaply attained.

\section{RDBs Go to SCMU in Cambridge}

IUCN has transferred to a special unit with an office in Cambridge, England, the major task of compiling and continuously updating the highly successful Red Data Books of Endangered Species. Of those already published, three mammals, amphibians and reptiles, and freshwater fish - will be in the new Unit's care, and also a new volume on invertebrates. Plants remain with the Threatened Plants Committee at Kew, and the bird volume arrangements await the arrival of the new executive director of ICBP in April. The Unit, called the Species Conservation Monitoring Unit (SCMU), will handle all RDB production, including printing and distribution. Its establishment is a recognition that the RDBs have become an indispensable tool not just to conservationists, for information and for action plans, but also for administrators, lawyers, government and other officials worldwide. The success of these volumes is probably beyond the most hopeful dreams of their inventor, Sir Peter Scott, and the SSC members who were in at the birth in the mid-1960s. Noel Simon, staff member of IUCN, was the first mammals editor; he was followed by SSC's former Executive Secretary, Dr Colin Holloway, helped in the major 1972 revision by Harry Goodwin, who was seconded to IUCN by the US Fish and Wildlife Service. Colin Holloway continued to do the annual updatings, helped in 1976 by Richard Fitter, FPS Honorary Secretary.

In the new Unit at 219c Huntingdon Road, Cambridge, the staff to date comprise Jane Fenton, who for nearly 12 years as wildlife assistant to Sir Peter has been in the thick of SSC affairs; Jane Thornback, mammals compiler who for the past three years has been doing the job in, and serviced by, the FPS office, and her assistant Jane Gilmour; and Dr Robert Pyle, Chairman of the SSC Lepidoptera Specialist Group. For collecting information SCMU's main sources will continue to be the thousand or more voluntary wildlife experts all over the world who are the backbone of IUCN; modern data-processing methods will be used to handle the material. SSC will use the information for its APX and NEEDS programmes - Action to Prevent Extinction, and Necessary Elements to Eliminate the Decline of Species (inventing acronyms is an SSC speciality!). And SCMU is pronounced (in Cambridge) 'skmew'. 